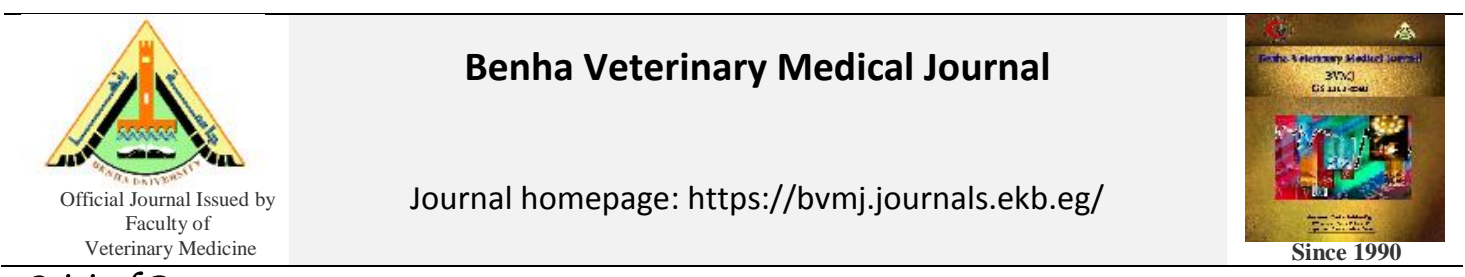

Original Paper

\title{
Curcumin and/or Hesperidin alleviates oxidative stress and hormonal alterations in a rat model of cyclophosphamide-induced premature ovarian failure
}

Yakout A. El Senosi1 ; Samy Ali Hussein1; Mohsen A.E.Aggag2 and Khaled Helmy Elnahas1*

${ }^{I}$ Biochemistry Department, Faculty of Veterinary Medicine, Benha University, Egypt.

${ }^{2}$ Theriogenology Department, Faculty of Veterinary Medicine, Benha University, Egypt.

\begin{tabular}{|c|c|}
\hline ARTICLE INFO & ABSTRACT \\
\hline $\begin{array}{l}\text { Keywords } \\
\text { Curcumin } \\
\text { Cyclophosphamide } \\
\text { Hesperidin } \\
\text { Oxidative stress } \\
\text { Premature ovarian failure }\end{array}$ & $\begin{array}{l}\text { Premature ovarian failure (POF) is a cessation of ovarian function in women less than } 40 \\
\text { years old. The atrophy of the ovary leads to decreased follicle storage, which leads to } \\
\text { irregular of the menstrual cycle, dysfunction of the ovary and causes infertility. The current } \\
\text { study was conducted to investigate the effects of curcumin (CRC) and hesperidin (HSP) on } \\
\text { POF in a female rat. POF was Caused by intraperitoneal (i. p.) injection of cyclophosphamide } \\
\text { ( } 200 \mathrm{mg} / \mathrm{kg} \mathrm{b} \text {. wt.) at the first day and then }(8 \mathrm{mg} / \mathrm{kg} \mathrm{b} \text {. wt./day) for the next } 14 \text { days. The } \\
\text { treatment with CRC ( } 100 \mathrm{mg} / \mathrm{kg} \mathrm{b} \text {. wt./day, i. p) and / or HSP ( } 80 \mathrm{mg} / \mathrm{kg} \mathrm{b} \text {. wt./day, i. p.) } \\
\text { were started and continued for } 14 \text { days after two weeks for POF induction. Ninety female rats } \\
\text { were classified into six groups. Group } 1 \text { (Control), Group } 2 \text { (POF-induced), Group } 3 \text { (POF+ } \\
\text { CRC), Group } 4 \text { (POF+HSP), Group } 5 \text { (POF+CRC+HSP) and Group } 6 \text { (Normal+CRC+HSP). } \\
\text { Serum follicle-stimulating hormone (FSH) and ovarian tissues malondialdehyde (MDA) } \\
\text { concentrations significantly increased, while serum estradiol (E2) level, ovarian tissues } \\
\text { reduced glutathione (GSH) and superoxide dismutase (SOD) markedly decreased in POF } \\
\text { group as compared with the control group. However, the } 3^{\text {rd }} \text {, the } 4^{\text {th }} \text { and the } 5^{\text {th }} \text { treated } \\
\text { groups had a significant increase in serum E2, ovarian tissues SOD activity and GSH level } \\
\text { and marked decrease in FSH and MDA concentrations compared with the POF group. The } \\
\text { histopathological changes in the three treated groups improved toward control group. } \\
\text { Conclusively, Hesperidin superior to curcumin in the alleviation of oxidative stress and } \\
\text { hormonal alterations in a rat model of cyclophosphamide-induced premature ovarian failure. }\end{array}$ \\
\hline
\end{tabular}

\section{INTRODUCTION}

Ovarian disorders are the diseases that affected or Focused on the ovaries. The defect in the ovarian function usually causing anovulatory infertility (Eweka and Om'Iniabohs, 2011). Corpus luteum and the follicle are the main 2 endocrine glands found in the ovaries. The corpus luteum produces progesterone which acts on the implantation of the embryo in the uterus. The follicles produce estrogens that control mammary glands and uterine lining development during the menstrual cycle. The female reproduction is affected by many environmental factors and chemotherapeutic agents (Bojanic et al., 2009). Premature ovarian failure is an example of the disorders of the ovaries. It is the cessation of the ovarian function with increasing in gonadotrophin level and decreased in estrogen level before or at the age of 40 years (Santoro, 2003).

Cyclophosphamide is the immunosuppressive, chemotherapeutic agent that used for auto-immune diseases and neoplastic treatment. It is the most common anticancer drug that used for the treatment of breast cancer and other malignant tumors treatment (Tomao et al., 2010).

Cancer treatment by chemotherapeutic drugs/chemical materials in combined form or single form are used for alleviation of cancer or for reducing the symptoms and prolongation the life (Thomson et al., 2002).

The chemotherapy side effects on reproduction in female survivors include increased infertility rate, early menopause and cause progressive and irreversible damage to the ovaries that lead to premature ovarian failure (Waxman, 1983; Gonfloni et al., 2009). Also, studies on chemotherapy treatment have shown that in spite of the increased successes in cancer treatment, it induces gonadal failure in the cancer survivors (Richman and Green, 2004). Curcumin is a yellow color compound where found in turmeric and is native to India and Southeast Asia. It has a bitter taste, earthy odor, mostly used in culinary (Goel et al., 2008). Now, it is available in supplements that contain higher curcumin concentration (Sharma et al., 2005). Also, it has a strong antioxidant and anti-inflammatory action. In addition to its healing effects (Duvoix et al., 2005).

Hesperidin and other similar bioflavonoids are called vitamin P (Garg et al., 2001). Hesperidin is found in citrus fruits, such as grapefruit, lime, orange, and lemon. The percentage of hesperidin in citrus fruits varies according to species (Abad-García et al., 2012). Many research showed that hesperidin has therapeutic antioxidant (Yang et al., 2012), neuroprotective (Hwang and Yen, 2008),

* Corresponding author: Khaled Helmy Elnahas, e.mail:khelmy762@gmail.com 
antineoplastic (Lee et al., 2010), antitumor, antiallergic, hypolipidemic, vasoprotective and anti-inflammatory effects (Saiprasad et al., 2013).

Protection of the ovarian follicle pool and prevention of POF is receiving an increasing attention to recover the quality of life of cancer patients treated by chemotherapy (Paluch-Shimon et al., 2016). Accordingly, this study was introduced to show the potential effects of some natural antioxidant agents (curcumin and hesperidin) in lowering the risk of cyclophosphamide, alleviates oxidative stress, hormonal alterations and preventing premature ovarian failure-induced in a rat model.

\section{MATERIAL AND METHODS}

\subsection{Experimental animals:}

Animals in this experimental study were obtained from the Faculty of Veterinary Medicine, Benha University, Egypt. These include 90 female albino rats, Aged 3-4 weeks and weighted $(200 \pm 10 \mathrm{~g})$. Each group of rats were housed in metal cages and supplied clean and fresh drinking water ad-libitum. Female rats were kept in constant nutritional and environmental conditions throughout the period of the study. The rats were left for acclimatization nearly 2 weeks before the beginning of the experiment.

\subsection{Chemicals and drugs:}

Chemicals and drugs used in this study were:

\subsubsection{Cyclophosphamide (CP) (97\%)}

Cyclophosphamide was purchased from Al-Dawlya Company. It was dissolved in $0.9 \% \mathrm{NaCl}$ and injected intraperitoneally (i. p.) in a dose (200 mg/kg b. wt.) of the first day, and then $(8 \mathrm{mg} / \mathrm{kg} \mathrm{b}$. wt./day) for the next 14 days (Rauf et al., 2018).

\subsubsection{Curcumin $(95 \%)$ :}

Curcumin (CRC) was purchased from Al-Dawlya Company. It was dissolved in $7 \%$ dimethyl sulfoxide and $0.9 \% \mathrm{NaCl}$ and injected intraperitoneally in a dose (100 $\mathrm{mg} / \mathrm{kg}$ b. wt./day, i. p.) for 2 weeks (Rauf et al., 2018).

\subsubsection{Hesperidin (95\%):}

Hesperidin (HSP) was purchased from Al-Dawlya Company. It was dissolved in $7 \%$ dimethyl sulfoxide and $0.9 \% \mathrm{NaCl}$ and injected intraperitoneally in a dose $(80$ $\mathrm{mg} / \mathrm{kg} \mathrm{b}$. wt./day, i. p.) for 2 weeks (Hosseinimehr and Nemati, 2006).

\subsection{Induction of Premature ovarian failure:}

Premature ovarian failure in female albino rats was induced by intraperitoneal (i. p.) injection of cyclophosphamide (200 mg/kg b. wt.) in the first day and then $8 \mathrm{mg} / \mathrm{kg} \mathrm{b}$. wt./ day for the next 14 days (Rauf et al., 2018). Two weeks after the beginning of the experiment, serum folliclestimulating hormone (FSH) and ovarian tissues MDA concentrations of some rats in POF injected groups were highly increased, while serum estradiol (E2) level decreased. Two weeks after premature ovarian failure induction, CRC (100 mg/kg b. wt./day) and HSP $(80 \mathrm{mg} / \mathrm{kg}$ b. wt./day) were i. p. given and continued for 14 days.

\subsection{Animal grouping:}

Ninety female albino rats were classified into six groups. Every fifteen female rats were placed in individual cages. The experiment was upheld for approximately 28 days:
Group I (Control normal group): No drug was given for rats.

This was control group for all experimental non-treated groups.

Group II (POF-non treated group): rats injected with cyclophosphamide (200 mg/kg b. wt.) i. p. in the first day, and then $(8 \mathrm{mg} / \mathrm{kg} \mathrm{b}$. wt./day) for the next 14 days.

Group III (POF treated with CRC): after POF induction, rats received a daily dose of curcumin $(100 \mathrm{mg} / \mathrm{kg}$ b. wt./ day) i. p. for approximately two weeks, then they were sacrificed.

Group IV (POF treated with HSP): after POF induction rats received i. p. daily dose hesperidin $(80 \mathrm{mg} / \mathrm{kg} \mathrm{b}$. wt./day) and then sacrificed after 2 weeks of treatment.

Group $V$ (POF treated with $\mathrm{CRC}+\mathrm{HSP}$ ): after $\mathrm{POF}$ induction rats received daily curcumin $(100 \mathrm{mg} / \mathrm{kg} \mathrm{b}$. wt./ day) and hesperidin (80 mg/kg b. wt./day) i. p. and sacrificed after 2 weeks of treatment.

Group VI (Normal group treated with CRC+HSP): rats received curcumin $(100 \mathrm{mg} / \mathrm{kg} \mathrm{b}$. wt./day) and hesperidin $(80 \mathrm{mg} / \mathrm{kg}$ b. wt./day) i. p. for 2 weeks

\subsection{Sampling:}

Blood samples and specimens of the ovarian tissue were collected from all groups after 14 days from the onset of treatment with CUR and HSP.

\subsubsection{Blood samples:}

After overnight fasting of rats blood samples were collected in clean and screw caps tubes by ocular vein puncture for serum separation and centrifuged for 15 minutes at 2500 RPM. The clear serum was separated by pipette and kept in the dry sterile tube in a deep freeze at $20{ }^{\circ} \mathrm{C}$ until used for determination of FSH and E2.

2.5.2. Ovarian tissue specimens for biochemical analysis: Rats were euthanized at the end of the experiment under light ether anesthesia. Both ovaries were isolated immediately, and one of them was stored at $-20^{\circ} \mathrm{C}$ after cleaned by rinsing with cold saline for biochemical tests. All ovarian samples were used for the determination of reduced glutathione (GSH) level, superoxide dismutase (SOD) activity and malondialdehyde (MDA). Briefly, ovarian tissues were cut, weighted and cut into small pieces, and homogenized in 9 volumes of ice-cold 0.05 $\mathrm{mM}$ potassium phosphate buffer $(\mathrm{pH} 7.4)$ by a glass homogenizer to make $10 \%$ homogenates, centrifuged at $6000 \mathrm{RPM}$ for 15 minutes at $4{ }^{\circ} \mathrm{C}$ then the supernatant was used to determine the concentration of MDA and SOD activity. Also, $0.2 \mathrm{~g}$ of ovarian tissues were cut into tiny pieces and homogenized with a glass homogenizer in 0.4 $\mathrm{ml}$ of $25 \%$ metaphosphoric acid (MPA), then $1.4 \mathrm{~mL}$ of distilled water was added, mixed, incubated for 1 hour and centrifuged for $10 \mathrm{~min}$ at $3000 \mathrm{RPM}$ then the clean supernatant was removed and used for determination of GSH concentration.

2.5.3. Ovarian tissue specimens for histopathological examination

The other ovary was saved in $10 \%$ buffered neutral formalin. The specific tissue was rinsed in water, by graded series of alcohols occur dehydration and embedded in paraffin wax after cleared in xylene. cut $5 \mathrm{~m}$ solid sections and stained with Hematoxylin and Eosin (H\&E) (Bancroft and Stevens, 1996) and subjected for microscopical examination. 


\subsection{Biochemical analysis:}

Quantitative determination of serum Follicle-stimulating hormone concentration was done by using Enzyme-linked immunosorbent assay (ELISA) kit (CALBIOTECH Co.) with a catalog No. TE187S. Quantitative determination of Estradiol (E2) level by chemiluminescent immunoassay using the Access Immunoassay Systems was carried out using (Beckman Coulter. Co) with a catalog No. 33540. Moreover, ovarian tissue Superoxide dismutase (SOD) activity, Malondialdehyde (MDA) concentration and reduced glutathione $(\mathrm{GSH})$ concentration were determined according to the methods described formerly (Mesbah et al., 2004; Akerboom et al., 1981; Beauchamp and Fridovich, 1971), respectively.

\subsection{Statistical Analysis:}

SPSS program version 16 was used in Statistical analysis and correlations (Renno et al., 2008). Data are given as Mean \pm standard error mean (SEM). Student " $t$ " test and analysis of variance (ANOVA) followed by Bonferroni's post hoc analysis were used for comparisons between groups. The level of statistical significance was set at probability $\mathrm{P}<0.05$.

\section{RESULTS}

3.1. Hormonal and biochemical changes

Effect of CRC and/or HSP administration on serum FSH and E2 levels and ovarian tissue GSH, L-MDA concentrations and SOD activity in cyclophosphamideinduced premature ovarian failure in female rats is presented in table (1). Serum FSH and ovarian tissues MDA concentrations significantly increased, while serum E2 level, ovarian GSH level and SOD activity markedly decreased in POF group as compared with the control group. However, a significant increase in serum E2, ovarian tissues GSH level and SOD activity with the marked decrease in serum FSH and ovarian tissue MDA concentrations were observed in groups of rats treated with CRC or/and HSP when compared with the POF group. Additionally, serum E2 and FSH level, ovarian SOD activity, GSH concentration and MDA concentrations in CRC + HSP treated normal rats showed non-significant changes compared with control normal group.

Table 1 Effect of curcumin and/or hesperidin administration on Serum FSH and E2 concentrations and ovarian tissue GSH, SOD and L-MDA in cyclophosphamide -induced premature ovarian failure in female rats.

\begin{tabular}{|c|c|c|c|c|c|}
\hline $\begin{array}{l}\text { Parameters } \\
\text { Animal groups }\end{array}$ & $\begin{array}{c}\text { FSH } \\
(\mathrm{ng} / \mathrm{ml})\end{array}$ & $\begin{array}{c}\mathrm{E} 2 \\
(\mathrm{pg} / \mathrm{ml})\end{array}$ & $\begin{array}{c}\mathrm{GSH} \\
\text { (mmol/g. tissue) }\end{array}$ & $\begin{array}{c}\text { SOD } \\
\text { (U/g.tissue ) }\end{array}$ & $\begin{array}{c}\text { L-MDA } \\
\text { (nmol/g. tissue ) }\end{array}$ \\
\hline G1: (control) & $6.22 \pm 0.57^{\mathrm{c}}$ & $88.04 \pm 2.47^{\mathrm{ab}}$ & $51.85 \pm 3.18^{\mathrm{a}}$ & $101.60 \pm 2.32^{\mathrm{c}}$ & $4.85 \pm 0.56^{\mathrm{b}}$ \\
\hline G2: (POF) & $25.19 \pm 1.31^{\mathrm{a}}$ & $30.61 \pm 2.83^{\mathrm{d}}$ & $31.8 \pm 3.05^{\mathrm{b}}$ & $67.73 \pm 3.96^{\mathrm{d}}$ & $13.46 \pm 0.89^{\mathrm{a}}$ \\
\hline G3: (POF+CRC) & $8.52 \pm 0.90^{\mathrm{b}}$ & $56.08 \pm 3.55^{\mathrm{c}}$ & $53.53 \pm 3.32^{\mathrm{a}}$ & $106.72 \pm 3.54^{\mathrm{bc}}$ & $2.92 \pm 0.40^{\mathrm{d}}$ \\
\hline G4: (POF+HSP) & $8.10 \pm 0.23^{\mathrm{bc}}$ & $61.95 \pm 4.49^{\mathrm{c}}$ & $53.97 \pm 3.04^{\mathrm{a}}$ & $109.89 \pm 4.92^{\text {abc }}$ & $3.13 \pm 0.32^{\mathrm{cd}}$ \\
\hline G5:(POF+CRC+HSP) & $6.67 \pm 0.39^{\mathrm{bc}}$ & $79.13 \pm 2.47^{\mathrm{b}}$ & $57.52 \pm 3.81^{\mathrm{a}}$ & $116.32 \pm 2.56^{\mathrm{ab}}$ & $3.62 \pm 0.31^{\mathrm{bcd}}$ \\
\hline G6: (CRC+HSP) & $6.05 \pm 0.43^{c}$ & $89.01 \pm 2.94^{\mathrm{a}}$ & $59.05 \pm 4.55^{\mathrm{a}}$ & $118.73 \pm 5.04^{\mathrm{a}}$ & $4.50 \pm 0.32^{\mathrm{bc}}$ \\
\hline
\end{tabular}

Data are presented as (Mean \pm S.E). Mean values with different superscript letters in the same column are significantly different at (P $₫$ ).05).

\subsection{Histopathological examination:}

In the control group, the ovarian tissue presented a normal histological aspect. The primordial follicle, multilaminar primary follicles, secondary follicles and corpus luteum showed normal appearances (Fig. 1). In the POF group, Hemorrhage in the ovarian stroma with vascular congestion as well as hemorrhage around the CL were observed, occur prominent mononuclear cell infiltration beneath the germinative epithelium with destruction of ovarian follicles were also demonstrated (Fig. 2). In the POF + CRC group (treated group), there were mature and immature follicles in association with wide area of interstitial stromal cells (Fig. 3). In the POF + HSP group (treated group), there were mature and immature follicles in association with wide area of interstitial stromal cells and CL were observed (Fig. 4). In the POF + CRC + HSP group (treated group), All histopathological parameters were improved after the injection of CRC and HSP and a normal unilaminar and multilaminar primary follicles, Graafian follicles, secondary follicles, CL structures and decreased vascular congestion (Fig. 5). In the CRC + HSP group, there were multiple mature follicles with interstitial stromal cells as well as CL at the cortex (Fig. 6).

\section{DISCUSSION}

Cyclophosphamide (CP) is a chemotherapeutic drug and used for the treatment of cancer, which has the cytotoxic and immunosuppressive effects (Wei et al., 2018).

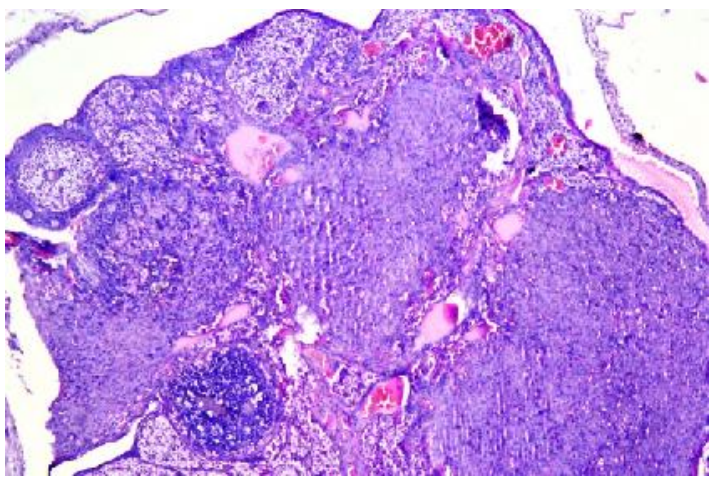

Fig. 1 Ovary of rat in group (1) showed normal structure of the different stages of the follicles with primordial oocytes as well as corpus luteum and few interstitial stromal cells (H\&E, x16).

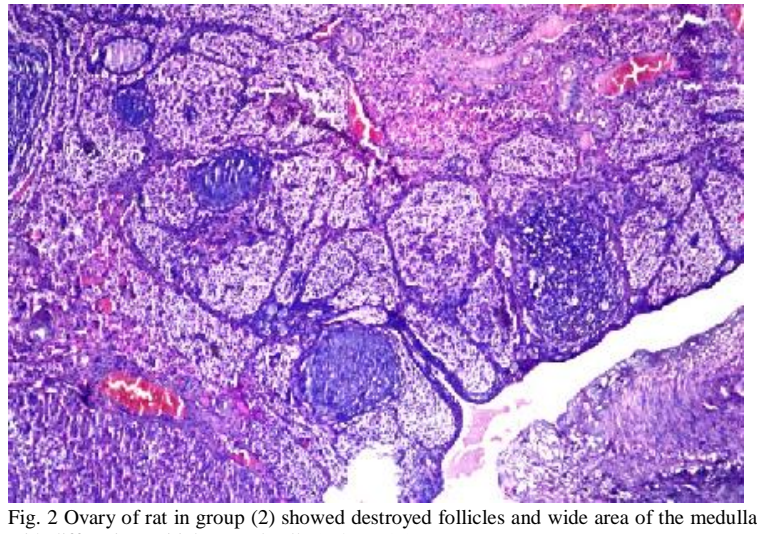

Hith 2 Ovary of rat in group (2) showed destroyed 
Cyclophosphamide drugs destroy ovarian follicles and alter ovarian function, which affects fertility and causes premature ovarian failure (POF). After cyclophosphamide injection, the female albino rat ovaries were damaged by the drugs. The follicles of the granulosa cells were killed in the development stage, and the serum concentration of FSH was increased while the concentration of E2 secretion was decreased. High levels of serum FSH indicate the ovarian toxicity degree induced by CP. FSH levels merged with E2 levels are important for the prediction of ovarian reserve (Zhang et al., 2015). Moreover, FSH can enhance the transformation of The phosphatidylinositol-3-kinase/ protein kinase B (PI3K-Akt) in ovarian granulosa cells from the inactive form to Activate phosphorylated Akt (pAkt) (Du and Tsichlis, 2005). The activate phosphorylated Akt (p-Akt) enhanced the synthesis of proteins and maturation of the granulosa cells of the ovaries to produce extra estradiol. However, due to the granulosa cell destruction causes the reduction in the expression of FSH receptors in cells and the effects of FSH cannot be extended. At the same time, the synthetic sites of E2 decreases.

In the current study serum FSH and ovarian tissue MDA concentration was significantly increased while serum E2 level decrease, the level of GSH level and SOD activity markedly decreased in POF group as compared with the control group. Cyclophosphamide is the Ovotoxic chemotherapeutic drugs, which triggers apoptosis and causes severe oxidative stress in ovarian tissue. Meirow et al. (2010) demonstrated that treatment with cyclophosphamide destroys ovarian follicles by inducing granulosa cell apoptosis and declining of ovarian GSH levels. The active metabolites of $\mathrm{CP}$ are detoxified by conjugation with GSH. Cyclophosphamide could seriously damage ovarian endocrine function by increasing FSH and decreasing E2 hormones and induce infertility due to its gonadal toxicity. The metabolic activation of cyclophosphamide completed via oxidation by hepatic enzymes cytochrome p450 to the reactive metabolite phosphoramide mustard (PM). Follicular damage is the main cause of ovarian failure and infertility induced by chemotherapy. The follicles of the ovary have been destroyed by $\mathrm{CP}$ by targeting the ovarian granulosa cells in rats and reduction in the number of primordial, primary, secondary and mature Graafian Follicle (Sato et al., 2009). These results were definite by histopathological changes of ovarian tissues that described by damaging of rapidly dividing granulosa cells in the developing follicles after $\mathrm{CP}$ treatment.

Oxidative stress results from the imbalance between the antioxidant defense mechanism (CAT activities, GSH concentration and SOD level) and free radicals, which leads to the inactivation of many enzymes and lipid peroxidation. Antioxidants are factors that prevent or neutralize free radicals (Zielinska et al., 2001). Glutathione is the intracellular antioxidant compound that made detoxification and elimination of toxins and carcinogens (Hagen et al., 2000). Also, oxidative stress made disturbances of the redox-regulated cellular mechanism by disruption of cellular redox circuits, resulting in disturbances of redox-regulated cellular processes. Moreover, Hydrogen peroxide $\left(\mathrm{H}_{2} \mathrm{O}_{2}\right)$ make inhibition for steroidogenesis in ovarian cells (Agarwal et al., 2005). ROS detoxification is very important for the maturation of oocyte and the development of the embryo. If the antioxidant system fails to neutralize ROS and RNS, the unsaturated lipids were converted to peroxides and lipid peroxidation formed leading to the interference of MDA with the ovarian reproductive functions.

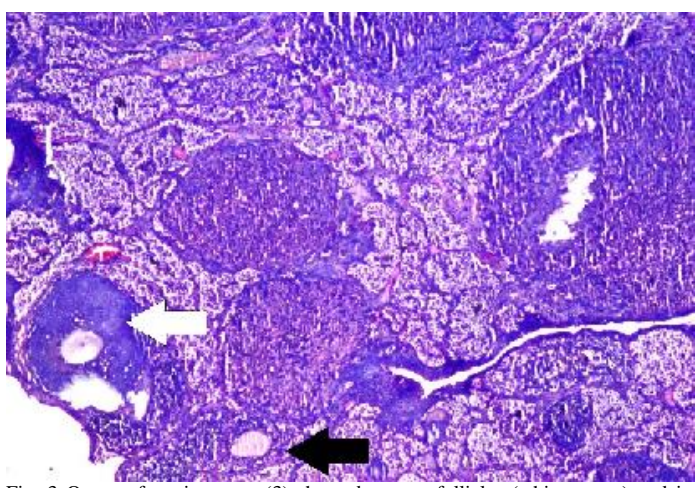

Fig. 3 Ovary of rat in group (3) showed mature follicles (white arrow) and immature follicles (black arrow) with interstitial stromal cells (H\&E, x16)

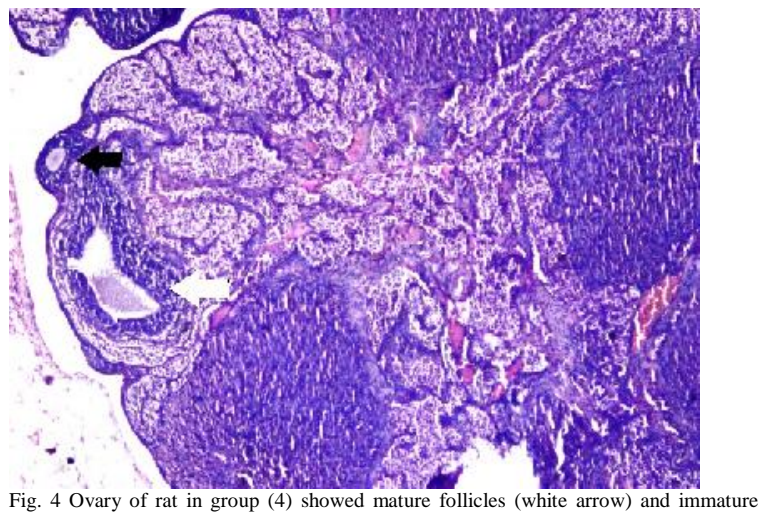
Fig. 4 Ovary of rat in group (4) showed mature follicles (while

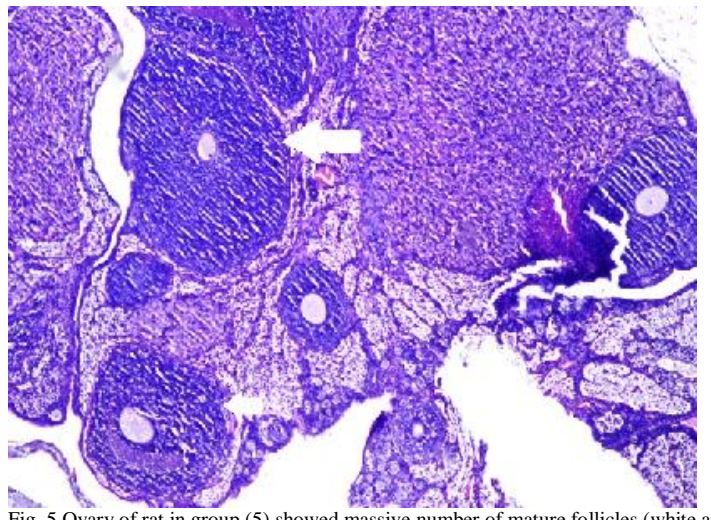
Fig. 5 Ovary of rat in group (5) showed massive number of mature follicles (white arrow) with few interstitial stromal cells (H\&E, x16)

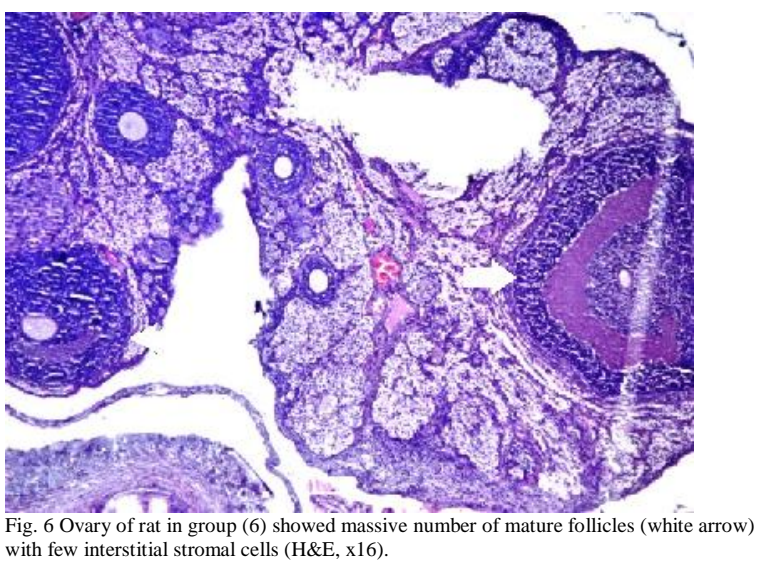


The lipid peroxidation of the mucosal tissue of the ovary increased by $\mathrm{CP}$ toxicity via the increasing of the MDA concentration and decreasing in the GSH level and ovarian SOD activity (Devine et al., 2012).

GSH is the very important antioxidant in cells which plays a major role in the maintenance of the intracellular redox balance and defense against oxidative stress (Dey and Cederbaum, 2006). Furthermore, cyclophosphamide causes the overproduction of ROS and RNS free radicals due to its induces oxidative stress. Together, SOD and GSH are scavenging for these free radicals. SOD is very important enzyme for the regulation of ovulation and the development of the follicles, increasing MDA levels indicated oxidative stress and tissue damage. In contrast, increasing SOD activity and GSH levels reflect tissue healing. Oxidative stress was induced apoptosis by preventing the nuclear and cytoplasmic ripeness of oocytes and leads to ovarian failure (Devine et al., 2012).

Curcumin has a great antioxidant effect comparable to the known strong antioxidant compounds. This situation makes its potential factor in the treatment of many diseases. Curcumin has sweeping effects to many free radicals mainly hydrogen peroxide and also superoxide anions, nitrogen dioxide radicals, hydroxyl radicals. Likewise, it reduced oxidative stress by increasing levels of antioxidant enzymes such as superoxide dismutase, catalase, glutathione peroxidase. Many studies revealed that curcumin inhibits lipid peroxidation, lipid degradation and oxidative DNA damage (Goel et al., 2008). The antioxidant effect of Curcumin preventing the generation of superoxide radical and hydrogen peroxide (Ak and Gulcin, 2008). The antioxidant property of curcumin very important for the reproductive system protection from the damaging effect of free radicals (Agarwal et al., 2003). Moreover, curcumin is mainly involved in the inhibition of lipid peroxidation processes by scavenging free radicals. curcumin posture itself within the membrane of the cell due to it could protect the cell from oxidative damage (Menon and Sudheer, 2007). On the other hand, Hesperidin was known as flavonoids that make scavenging of ROS, suppression of enzymes participate in the production of ROS and regeneration of endogenous antioxidants (Zielinska et al., 2001).

In the present study CRC and HSP treatment are ameliorate signs of ovarian reserve after CP-induced Premature ovarian failure in rats as shown by a significant increase in serum E2, ovarian tissues SOD activity and GSH level with the marked decrease in serum FSH and ovarian tissue MDA concentrations in CRC or/and HSP treated group when compared with the POF group. Also, CRC or/and HSP administration improved the histopathological alterations in ovarian tissue such as destroyed follicles and less mature follicles without corpus luteum observed in rat ovaries exposed to $\mathrm{CP}$ treatment. Also, Hesperidin scavenging power is related to their B-ring catechol structure that gives the highest stability during of AroxylRadical formation and participation in electron dislocation. the 3' and 5' $\mathrm{OH}$ functions together give a highly scavenging radical potential (Andersen and Markham, 2006).

The histopathology of rat ovaries showed that the destruction of ovarian follicles and a hemorrhage in the ovarian stroma, vascular congestion, around the corpus luteum and beneath the germinative epithelium occur prominent mononuclear cell infiltration in the POF group compared to the control group and the treated groups.
These results were in agreements with previous reports which demonstrated that a single injection of $200 \mathrm{mg} / \mathrm{kg}$ $\mathrm{CP}$, in adult rats, destroyed all types of follicles. This destruction was caused by induction of apoptosis in granulosa cells of these follicles and was associated with activation of caspase- 9 and caspase- 3 (Sato et al., 2009). While after the treatment with Curcumin and / or Hesperidin we showed that improvement of histological parameters, such as hemorrhage, vascular congestion, and mononuclear cell infiltration and a normal unilaminar and multilaminar primary follicles, secondary follicles, Graafian follicles, corpus luteum structures and a massive number of mature follicles were observed in ovarian tissue of the treated groups compared to the POF group. These results were in agreements with previous reports which demonstrated that the investigation of the effect of CRC on the protection of gastric mucosa against stress-induced gastric mucosal damage and demonstrated that the number of experimental stress-induced gastric lesions was markedly reduced by CRC treatment (Czekaj et al., 2016).

\section{CONCULOSIONS}

From the obtained results it could be concluded that, curcumin (CRC) and/or Hesperidin (HSP) treatment in rats with cyclophosphamide-induced premature ovarian failure (POF) had a useful effect on decreasing ovarian damage by amelioration ovarian oxidative stress, histopathological damage and hormonal alterations

\section{REFERENCES}

1. Abad-García, L. A., Berrueta, S. Garmón-Lobato, A., Urkaregi, B.,Gallo and Vicente (2012). Chemometric characterization of fruit juices from spanish cultivars according to their phenolic compound contents: I. Citrus fruits. J. Agric. Food Chem., 60(14), 3635-3644.

2. Agarwal, A., Gupta, S., Sharma, R.K. (2005). Role of oxidative stress in female reproduction. Reprod Biol Endocrinol. 3: 28-39.

3. Agarwal, A., Saleh ,R.A. and Bedaiwy, M.A. (2003): Role of reactive oxygen species in the pathophysiology of human reproduction. Fertil. Steril., 79(4), 829-43.

4. Ak, T. and Gulcin, I. (2008): Antioxidant and radical scavenging properties of curcumin. Chem Biol Interact., 174(1): 27- 37 .

5. Akerboom, T.P.M. and Seis, H. (1981). Assay of glutathione, glutathione disulfide and glutathione mixed disulfide in biological samples. Methods Ezymol., 77: 373-82.

6. Andersen, O.M. and Markham, K.R. (2006): Flavonoids chemistry, biochemistry and applications". CRC Press, Boca Raton. Pp. 19-25.

7. Banchroft, J.D., Stevens, A. and Turner, D.R. (1996): Theory and Practice of Histological Techniques. $4^{\text {th }}$ Edition, Churchill Livingstone, London, Toronto.

8. Beauchamp, C. and Fridovich, I. (1971): Superoxide dismutase: Improved assay and assay applicable to acrylamide gels. Anal. Biochem., 44: 276-287.

9. Bojanic, V., Bojanic, Z., Najman, S., Savic, T., Jakovljevic, V., Najman, S., Jancic, S.(2009). Diltiazem prevention of toxic effects of monosodium glutamate on ovaries in rats. Gen Physiol. Biophys., 28: 149-154.

10. Czekaj, R., Majka, J., Ptak-Belowska, A., Szlachcic, A., Targosz, A., Magierowska, K., Strzalka, M., Magierowski, M., Brzozowski, T.(2016): Role of curcumin in protection of gastric mucosa against stress-induced gastric mucosal damage. Involvement of hypoacidity, vasoactive mediators and sensory neuropeptides. J. Physiol. Pharmacol., 67(2): $261-275$ 
11. Devine, P.J., Perreault, S.D., Luderer, U.(2012). Roles of reactive oxygen species and antioxidants in ovarian toxicity. Biol Reprod. 86: 1-10.

12. Dey, A., Cedderbaum, A.I. (2006) : Alcohol and oxidative liver injury . Hepatology, 43, Suppl.1: S63-S74.

13. Du, K. and Tsichlis, P.N.(2005): Regulation of the Akt kinase by interacting proteins. Oncogene, 24, 7401-7409.

14. Duvoix, A., Blasius, R., Delhalle, S.(2005) Chemopreventive and therapeutic effects of curcumin. Cancer Lett. 223(2):181-190.

15. Eweka, A.O., Om'iniabohs, F.A.E.(2011). Histological studies of the effects of monosodium glutamate on the ovaries of adult wistar rats. Ann Med Health Sci Res.1: 3744.

16. Garg, A., Garg, S. Zaneveld, L. J. D. and Singla, A. K.(2001). Chemistry and pharmacology of the Citrus bioflavonoid hesperidin. Phytotherapy Research 15(8): 655669.

17. Goel, A., Kunnumakkara, A,B. and Aggarwal, B.B.( 2008): Curcumin as "curecumin": from kitchen to clinic. Biochemical Pharmacology 75(4), 787- 809.

18. Gonfloni, S., Di Tella, L., Caldarola, S., Cannata, S.M., Klinger, F.G., Di Bartolomeo, C., Mattei, M., Candi, E., De Felici, M., Melino, G., Cesareni, G. (2009). Inhibition of the c-Abl-TAp63 pathway protects mouse oocytes from chemotherapy-induced death. Nat Med 15, 1179-1185.

19. Hagen, T.M., Vinarsky, V., Wehr, C.M. and Ames, B.N(2000): (R)-alpha-lipoic acid reverses the age-associated increase in susceptibility of hepatocytes to tert-butyl hydroperoxide both in vitro and in vivo. Antioxidants and Redox Signaling fall . 2(3): 473-83.

20. Hosseinimehr, S.J. and Nemati, A.(2006) : Radioprotective effects of hesperidin against gamma irradiation in mouse bone marrow cells. Int. J. Radiol.,79. 415-418.

21. Hwang, S. L. and Yen, G. C.(2008). Neuroprotective Effects of the Citrus Flavanones against H2O2-Induced Cytotoxicity in PC12 Cells. J. Agric. Food Chem., 56(3), 859-864,

22. Lee, K. H., Yeh, M. H., Kao, S. T., Hung, C. M. and Yeh, C. C. (2010). The inhibitory effect of hesperidin on tumor cell invasiveness occurs via suppression of activator protein 1 and nuclear factor-kappaB in human hepatocellular carcinoma cells. Toxicology Letters, 194(1-2): 42-49.

23. Meirow, D., Biederman, H., Anderson, R.A., Wallace, W.H (2010): Toxicity of chemotherapy and radiation on female reproduction. Clin. Obstet. Gynecol. 53, 727-739.

24. Menon, V.P and Sudheer, A.R.(2007): Antioxidant and antiinflammatory properties of curcumin. Adv Exp Med Biol. 595: 105- 25

25. Mesbah, L., Soraya, B., Narimane, S. , Jean, P.F. (2004) protective effect of flavonides against the toxicity of vinblastine cyclophosphamide and paracetamol by inhibition of lipid - peroxydation and increase of liver glutathione. Haematol. 7 (1): 59-67.

26. Paluch-Shimon, S., Pagani, O., Partridge, A.H., Bar-Meir, E., Fallowfield, L., Fenlon, D., Friedman, E., Gelmon, K. Gentilini, O., Geraghty, J., (2016). Second international consensus guidelines for breast cancer in young women (BCY2). Breast. 26, 87-99.

27. Rauf, M., Osman, C., Sevil, E., Asli, C., and Nese, B.(2018) Beneficial effects of curcumin and capsaicin on cyclophosphamide-induced premature ovarian failure in a rat model. J Ovarian Re 26;11(1):33. doi: 10.1186/s13048-0180409-9..

28. Renno, W. M.; Alkhalaf, M.; Afsari, Z.; Abd-El-Basset, E. Mousa, A. 2008: Consumption of green tea alters glial fibriliary acidic protein immunoreactivity in the spinal cord astrocytes of STZ-diabetic rats. Nutr. Neurosci.; 11: 32-40.

29. Richman, S.B. and Green, K.B. (2004). Breast cancer in young woman. Cancer Chemoth. Fertil., 72: 1-5.

30. Saiprasad, G., Chitra, P., Manikandan, R. and Sudhandiran, G. (2013) : Hesperidin alleviates oxidative stress and down regulates the expressions of proliferative And inflammatory markers in azoxymethane-induced experimental colon Carcinogenesis in mice. Inflamm. Res 62: 425-440.

31. Santoro, N. (2003). Mechanisms of premature ovarian failure. Ann Endocrinol 64:87-92.

32. Sato, M.I., Shiozawa, K., Uesugi, T., Hiromatsu ,R., Fukuda, M., Kitaura, K., Minami, T., Matsumoto, S. (2009). Collaborative work on evaluation of ovarian toxicity. 7) Effects of 2- or 4- week repeated dose studies and fertility study of cyclophosphamide in female rats. J Toxicol Sci . 34 SP83-89.

33. Sharma, R.A., Gescher, A.J., Steward, W.P.(2005) Curcumin: the story so far. Eur J Cancer. 41(13).1955-1968.

34. Thomson, A.B., Critchley, H.O.D., Kelnar, C.J.H., Wallace, W.H.B., (2002). Late reproductive sequelae following treatment of childhood cancer and options for fertility preservation. Best Practice \& Research Clinical Endocrinology \& Metabolism 16,311-334.

35. Tomao, F., Spinelli, G.P., Panici, P.B., Frati, L. and Tomao, S. (2010). Ovarian function, reproduction and strategies for fertility preservation after breast cancer. Critical Reviews in Oncology/Hematology.76(1).1-12.

36. Waxman, J.(1983). Chemotherapy and the adult gonad: A review. J. R. Soc. Med. , 76, 144-148.

37. Wei ,T., Ling, L., Feng, X., Zhang, W., Xiong. Z (2018):Effects and mechanism of cyclophosphamide on the ovarian structure and function of rats with premature ovarian failure. Med. J. Chin. People's Lib. Army 43, 195-200.

38. Yang, H. L., Chen, S. C., Kumar, K. J. S. (2012) Antioxidant and anti-inflammatory potential of hesperetin metabolites obtained from Hesperetin administered rat serum: an ex vivo approach. J. Agric. Food Chem., 60(1): 522-532.

39. Zhang, Y., Ma, H., Wang, Y.(2015): Study on rat model of premature ovarian failure induced by cyclophosphamide. J. Ningxia Med. Univ., 37, 874-878.

40. Zielinska, M., Kostrzewa, A., Ignatowicz, E. and Budzianowski, J.(2001): The flavonoids, quercetin and isorhamnetin 3-O-acylglucosides diminish neutrophil oxidative metabolism and lipid peroxidation. Acta Biochimica. Polonica. 48(1):183-189. 